\title{
Management of Post-Circumcision Trapped Penis with Glanular Amputation
}

\author{
Adel M. Tolba*, Mohamed Nasr, Ahmed Abohashem, Mahmoud Abd-Elnaby, \\ Emad S. Ibrahim \\ Plastic Surgery Unit, Zagazig University, Zagazig, Egypt \\ Email: *abdelrahmantolba@yahoo.com
}

Received 7 May 2014; revised 5 June 2014; accepted 1 July 2014

Copyright (C) 2014 by authors and Scientific Research Publishing Inc.

This work is licensed under the Creative Commons Attribution International License (CC BY). http://creativecommons.org/licenses/by/4.0/

c) (7) Open Access

\begin{abstract}
A phenomenon known as trapped penis has numerous origins, including injudicious circumcision. Materials and Methods: Surgery for trapped penis with glanular amputation was performed for 5 children. The surgical policy in these cases included complete penile degloving, excising the scarring due to circumcision, fixing the penile skin at the penopubic and penoscrotal angles and reconstructing the penile skin with full thickness skin graft. Results: Improvement was noted in all cases. Conclusion: Surgery for hidden penis using full thickness skin graft achieves very satisfactory aesthetic and functional improvement.
\end{abstract}

\section{Keywords}

Trapped Penis, Circumcision, Amputated Penis

\section{Introduction}

An estimated one third of males worldwide are circumcised, with a very high prevalence in some countries and very low coverage in others. Circumcision can result in complications as with any surgical procedure [1]-[3]. Most commonly early complications may be minor and treatable as pain, bleeding, swelling or inadequate skin removal. However, major complications can occur during the procedure, including death from excess bleeding and amputation of the glans penis if the glans is not shielded during the procedure [4] [5]. Late complications include pain, wound infection, the formation of a skin-bridge between the penile shaft and the glans, infection, urinary retention, meatal ulcer, meatal stenosis, fistulas, loss of penile sensitivity, sexual dysfunction and edema of the glans penis [6].

Buried penis as described in the early 20th century is a penis of normal size that lacks an adequte sheath of

"Corresponding author.

How to cite this paper: Tolba, A.M., Nasr, M., Abohashem, A., Abd-Elnaby, M. and Ibrahim, E.S. (2014) Management of Post-Circumcision Trapped Penis with Glanular Amputation. Surgical Science, 5, 309-313.

http://dx.doi.org/10.4236/ss.2014.57052 
skin and is located beneath the integument of the abdomen, thigh, or scrotum. This condition is more common in children or obese prepubertal boys; however, it can also be seen in adults and has been observed in both circumcised and uncircumcised individuals. Marginal cases may not be diagnosed until adulthood, when increased fat deposition accentuates the problem.

Several classification systems of buried penis have been proposed, although none has been universally adopted in the literature. Usually, differentiation among the terms includes: concealed (before circumcision), trapped (cicatricial [scarred] after circumcision), and buried (associated with obesity) [7].

Trapped penis is a condition that can lead to urinary infections, balanitis, skin adhesions, misdirection of the urinary stream, and the inability to grasp the penis during urination. An abnormal appearance of the external genitalia may have psychological effects on the child and his family [8]. Fear to be discovered and teased by classmates may result in depression, feeling of inadequacy and insecurity. Parents are frequently worried about the future of their child [9].

Early surgical reconstruction may therefore benefit the child and parents as well. It is very important for the primary care physician to make a correct diagnosis and to promote timely referral [10].

This study was done to review the clinical presentations, time for surgical correction and outcome of our surgical technique to correct the trapped penis.

\section{Patients and Methods}

This study was conducted in Plastic Surgery Unit of Zagazig University Hospitals from March 2009 to January 2013 and included 5 cases of trapped penis with glanular amputation (Figure 1). All cases were evaluated clinically with emphasis on true length of the penis, the length of penile skin and presence of any inflammations or cicatrizing scars following circumcision. Great care was directed to preoperative penile hygiene.

During obtaining the informed consent, assessment of the expectations of patients and parents was done. This study was approved by the IRB (Institutional Review Board) of Zagazig University.

\section{Surgical Technique}

General anesthesia with endotracheal intubation was given to all cases. Surgical chemoprophylaxis was also done using broad spectrum third generation cephalosporin (cefotaxime sodium).

After application of urethral catheter, a circumferential incision $5 \mathrm{ml}$ below the tip of penis was done, and by using the Buck's fascia as the plane of dissection, the penis was degloved to the penopubic and penoscrotal junctions. Sharp dissection of the dysgenetic dartos fibers, to free the penis from its deep tethering including the suspensory ligament, was carried out.

Fixation was then performed by placement of absorbable sutures (polyglycolic acid 5/0) between the dermis of the skin shaft at the base of the penis and buck's fascia, lateral to the posterior neurovascular bundle and lateral to the urethra, thus restoring the penopubic and penoscrotal angles respectively.

Full thickness skin grafts were taken from a non-hirsute area and the penis was covered. The graft was fixed in place with several sutures, and non adherent compressive wound dressing was performed. The penis was fixed in a dorsal position and the dressing was removed after five days followed by stitch removal in the 8th postoperative day (Figure 2).

\section{Results}

This study included 5 patients with post-circumcision trapped penis with glanular amputation. Their ages ranged
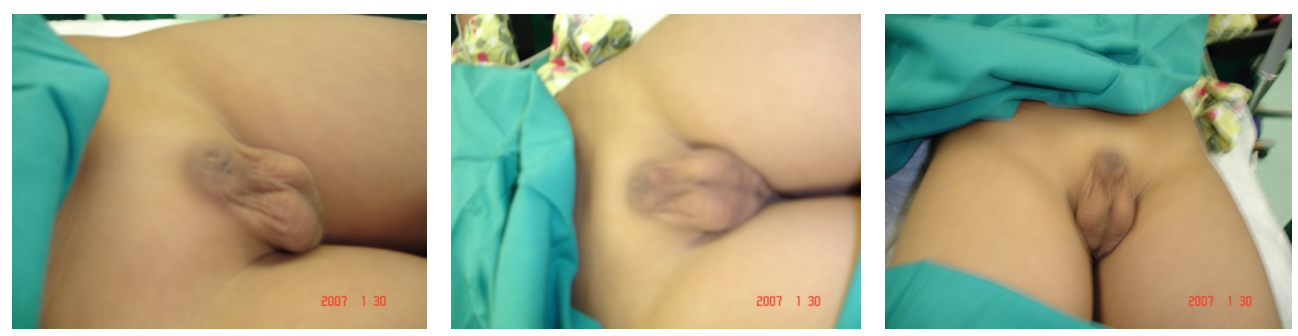

Figure 1. Preoperative. 
from 5 to 13 years (mean age was 8 years). Their presentation were bad cosmesis (80\%), psychological disturbance (60\%), phimosis (20\%), dysuria (40\%), dribbling between voids (80\%), recurrent UTI (40\%).

Diagnosis was completely made on clinical basis; no investigations were needed.

Mean follow-up period was 1 year. The only reported complication was partial graft loss that occurred in one patient only ( $20 \%$ of cases). This patient was managed conservalively by repeated daily dressing till spontaneous healing occurred after two weeks.

All patients showed an excellent result as regards to the postoperative length and cosmetic appearance of the penis and required no additional surgery with relief of preoperative symptoms (Figure 3 and Figure 4).
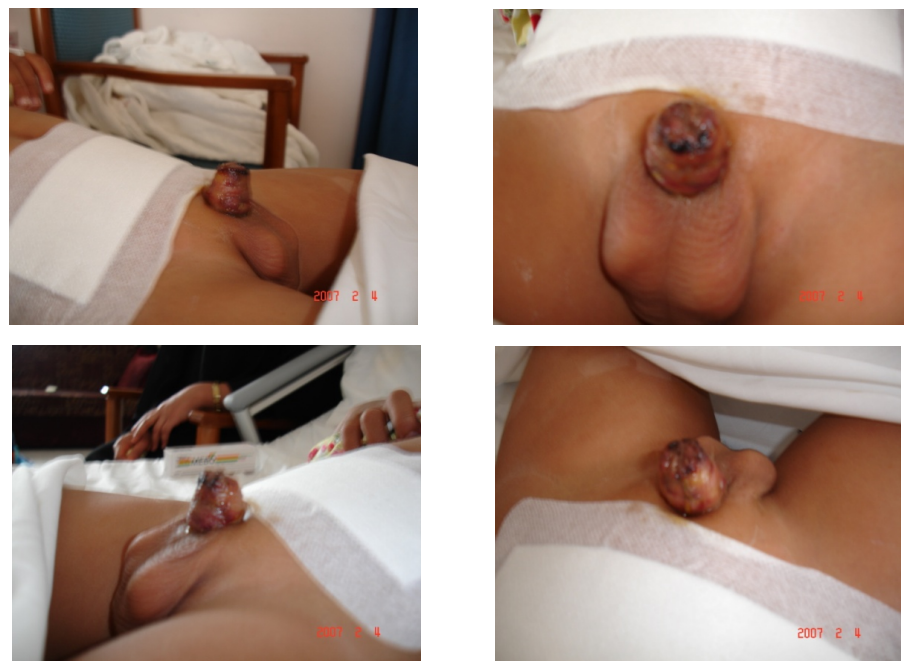

Figure 2. 7 days postoperative.
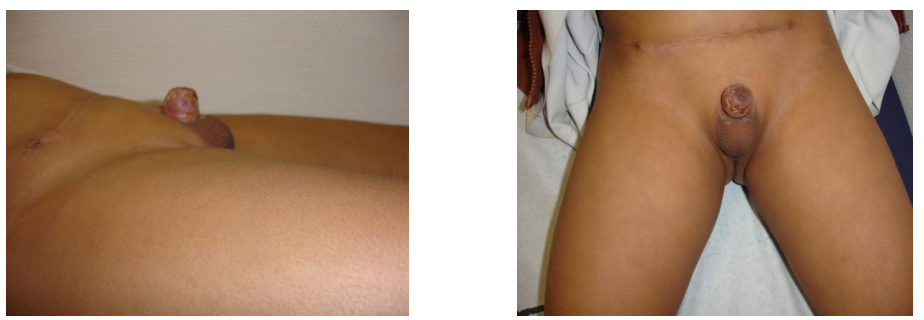

Figure 3. 15 days postoperative.
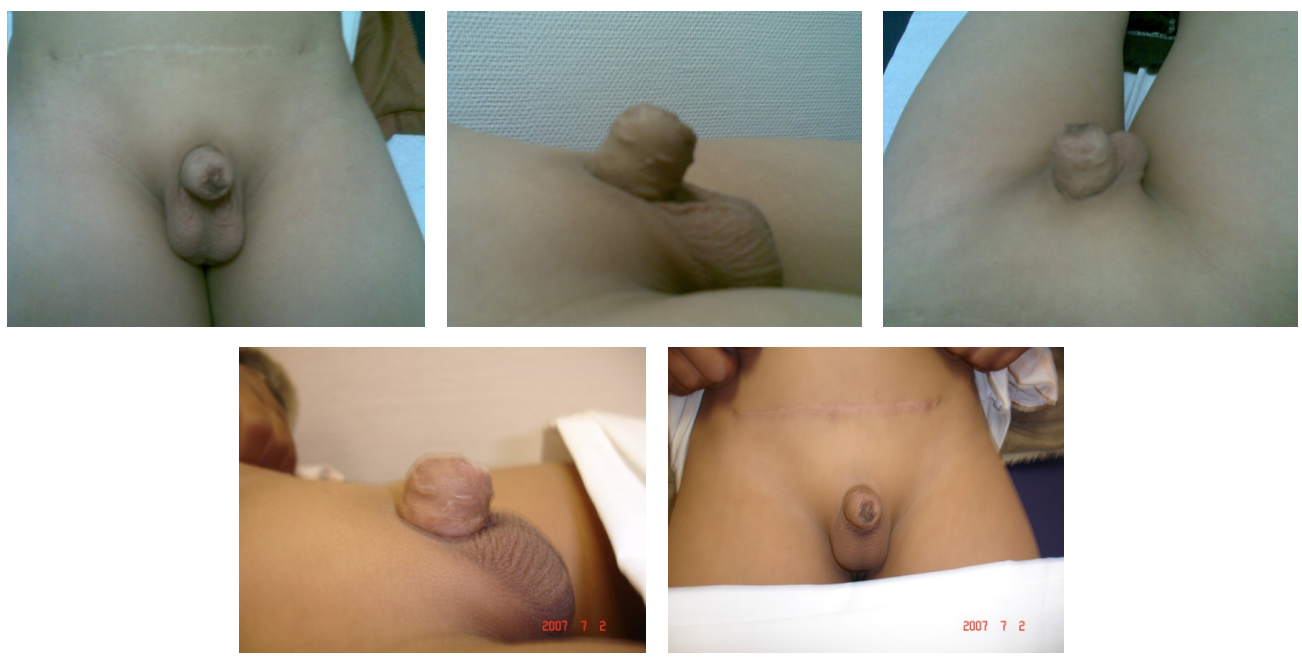

Figure 4. 5 months postoperative. 


\section{Discussion}

Concealed penis is an uncommon pathology with only 2 - 8 cases reported per year in large medical centres [11]. A concealed penis is defined as a phallus of normalsize buried in prepubic tissue (buried penis), enclosed in scrotal tissue (webbed penis), or trapped by scar tissue after penile surgery (trapped penis), while micropenis represents a penis length less than 2 standard deviations below the mean for age when measured in the stretched state and diminutive penis is seen when the penis is small, malformed or both secondary to epispadias, extrophy, severe hypospadias or intersex conditions [12]. This study included 5 patients with normal sized concealed penis with glanular amputation which were differentiated, before any treatment, from the micro penis or diminutive penis and, as mentioned, this needs only meticulous clinical examination.

Most pediatric cases with concealed penis present in neonates or prepubertal boys. The age in this study ranged from 5 years to 15 years. The timing of surgical repair of concealed penis is controversial; some prefer to defer surgical correction until school age while others advocate surgical intervention in infancy, and state that before 3 years of age, surgical correction is important so that the child is able to void while standing during the period of toilet training [13]. We think that surgery may be more helpful earlier rather than later as surgery at an early age relieves anxiety and improves self confidence.

Indications for surgical repair of concealed penis are numerous, for example, a concealed penis can hamper proper hygiene, trap urine and complicate voiding leading to repeated infections, secondary phimosis or even urinary retention [14] [15]. In addition, children with concealed penis are at a risk for psychological and social trauma [16].

Numerous techniques have been described for repairing the concealed penis. Variations have been proposed for different presumed etiologies and to simplify the procedure [17] [18].

The approach, which we used for correction of trapped penis is complete exteriorization of the penile shaft, with easy control of bleeding and application of fixation sutures to create the penoscrotal and penopubic angles.

So, the surgeon must be aware of these different techniques to tailor the operative steps to the particular needs and the anatomic aberrations in individual cases [19].

The goal of the treatment, after extensive loss of the penile skin, is to achieve good cosmetic appearance of the penis and restoring adequate sexual function. Skin grafting of the penile shaft is generally less successful and strictly depends on surgical technique and infection prophylaxis The most important prerequisite for graft survival is well vascularized "bed", appropriate tension, as well as firm compression of dressing over it [20] [21]. Skin graft could be harvested from non-hirsute skin, that has adequate elasticity to enable function of the penis in the flaccid and errect state, as well as, tactile sensation [22] [23]. Graft from the scrotum is the most similar but the skin is hirsute, unsuitable for the excessive skin loss. Split thickness skin graft was used in numerous reports successfully, but with the expressed shrinkage of the graft and sensitivity to infection. Full thickness skin graft was a successful technique and keeps elasticity of the skin better [24].

In elective cases with "trapped" penis, hypodermal tissue is kept in situ, so the circumstances for graft survival are substantially better than in cases with traumatic degloving of the penis, in whom skin with hypodermal tissue are removed and Buck's fascia exposed.

Most complications of trapped penis e.g. haematoma, penile edema and superficial infection are temporary and usually resolve by conservative measures [13], in our series we have only one patient who underwent partial loss of the skin graft and healed conservatively. Many series that reported long-term outcome of pediatric cases found that surgical correction resulted in excellent long-term cosmetic results. Surgery eliminated associated negative feelings, improved penile appearance and facilitated better hygiene [19]. The mean follow-up in this study was 1 year. Excellent results, regarding the general appearance, accessibility and easy hygiene were obtained in all patients.

\section{Conclusions}

Concealed penis has a variable etiology. Circumcision could be the initial cause or an aggravating factor. Early surgical correction of this problem is advocated; it relieves anxiety and improves self confidence.

Surgeons dealing with these cases should have a versatile approach for surgical correction.

Full thickness skin graft could be suggested as a preferable way for the skin substitution of the penile shaft due to the low contraction rate and good elasticity. 


\section{References}

[1] Weiss, H.A., Larke, N., Halperin, D. and Schenker, I. (2010) Complications of Circumcision in Maleneonates, Infants and Children: A Systematic Review. BMC Urology, 10, 2. http://dx.doi.org/10.1186/1471-2490-10-2

[2] WHO/UNAIDS (2008) Male Circumcision: Global Trends and Determinants of Prevalence, Safety and Acceptability. World Health Organization.

[3] Kaplan, G.W. (1983) Complications of Circumcision. Urologic Clinics of North America, 10, 543-549.

[4] Lerman, S.E. and Liao, J.C. (2001) Neonatal Circumcision. Pediatric Clinics of North America, 48, 1539-1557. http://dx.doi.org/10.1016/S0031-3955(05)70390-4

[5] Williams, N. and Kapila, L. (1993) Complications of Circumcision. British Journal of Surgery, 80, 1231-1236. http://dx.doi.org/10.1002/bjs.1800801005

[6] Gluckman, G.R., Stoller, M.L., Jacobs, M.M. and Kogan, B.A. (1995) Newborn Penile Glans Amputation during Circumcision and Successful Reattachment. Journal of Urology, 153, 778-779. http://dx.doi.org/10.1016/S0022-5347(01)67718-8

[7] Chopra, C.W., Ayoub, N.T., Bromfield, C. and Witt, P.D. (2002) Surgical Management of Acquired (Cicatricial) Buried Penis in an Adult Patient. Annals of Plastic Surgery, 49, 545-549. http://dx.doi.org/10.1097/00000637-200211000-00017

[8] Palmer, J.S., Elder, J.S. and Palmer, L.S. (2005) The Use of Betamethasone to Manage the Trapped Penis Following Neonatal Circumcision. Journal of Urology, 174, 1577-1578. http://dx.doi.org/10.1097/00005392-200510020-00015

[9] Alter, G.J. and Ehrlich, R.M. (1999) A New Technique for Correction of the Hidden Penis in Children and Adults. Journal of Urology, 161, 455. http://dx.doi.org/10.1016/S0022-5347(01)61922-0

[10] Smeulders, N., Wilcox, D.T. and Cuckow, P.M. (2000) The Buried Penis-An Anatomical Approach. BJU International, 86, 523-526. http://dx.doi.org/10.1046/j.1464-410X.2000.00752.x

[11] Espinosa, Ch.G., Castro, D.C. and Abril, R. (2011) Concealed Penis: Surgical Management. Revista Mexicana de Urología, 71, 128-131.

[12] Raboei, L. (2003) Surgical Management of a Concealed Penis. Saudi Medical Journal, 24, 550-552.

[13] Khaled, A.I. (2009) Surgical Correction of Concealed Penis. Annals of Pediatric Surgery, 5, 261-267.

[14] Donatucci, C.F. and Ritter, E.F. (1998) Management of the Buried Penis in Adults. Journal of Urology, 159, 420-424. http://dx.doi.org/10.1016/S0022-5347(01)63939-9

[15] Chuang, J.H. (1995) Penoplasty for Buried Penis. Journal of Pediatric Surgery, 30, 1256-1257. http://dx.doi.org/10.1016/0022-3468(95)90479-4

[16] Borsellino, A., Spagnoli, A., Vallasciani, S., Martini, L. and Ferro F. (2007) Surgical Approach to Concealed Penis: Technical Refinements and Outcome. Urology, 69, 1195-1198. http://dx.doi.org/10.1016/j.urology.2007.01.065

[17] Brisson, P., Patel, H., Chan, M. and Feins, N. (2001) Penoplasty for Buried Penis in Children: Report of 50 Cases. Journal of Pediatric Surgery, 36, 421-425. http://dx.doi.org/10.1053/jpsu.2001.21605

[18] Gillett, M.D., Rathbun, S.R., Husmann, D.A., Clay, R.P. and Kramer, S.A. (2005) Split-Thickness Skin Graft for the Management of Concealed Penis. The Journal of Urology, 173, 579-582. http://dx.doi.org/10.1097/01.ju.0000149606.27158.fa

[19] Chuang, J.H., Chen, L.Y., Shieh, C.S. and Lee, S.Y. (2001) Surgical Correction of Buried Penis: A Review of 60 Cases. Journal of Pediatric Surgery, 36, 426-429. http://dx.doi.org/10.1053/jpsu.2001.21606

[20] Ratner, D. (1998) Skin Grafting from Here to There. Dermatologic Clinics, 16, 75-90. http://dx.doi.org/10.1016/S0733-8635(05)70488-5

[21] Robson, M.C. and Krizek, T.J. (1973) Predicting Skin Graft Survival. Journal of Trauma-Injury Infection \& Critical Care, 13, 213-217. http://dx.doi.org/10.1097/00005373-197303000-00005

[22] Borsellino, A., Spagnoli, A., Vallasciani, S., Martini, L. and Ferro, F. (2007) Surgical Approach to Concealed Penis: Technical Refinements and Outcome. Urology, 69, 1195-1198. http://dx.doi.org/10.1016/j.urology.2007.01.065

[23] Wilson, C. and Wilson, M. (1959) Plastic Repair of the Denuded Penis. Southern Medical Journal, 52, $288-290$.

[24] Black, P.C., Friedrich, J.B., Engrav, L.H. and Wessells, H. (2004) Meshed Unexpanded Split-Thickness Skin Grafting for Reconstruction of Penile Skin Loss. The Journal of Urology, 172, 976-979.

http://dx.doi.org/10.1097/01.ju.0000133972.65501.44 
Scientific Research Publishing (SCIRP) is one of the largest Open Access journal publishers. It is currently publishing more than 200 open access, online, peer-reviewed journals covering a wide range of academic disciplines. SCIRP serves the worldwide academic communities and contributes to the progress and application of science with its publication.

Other selected journals from SCIRP are listed as below. Submit your manuscript to us via either submit@scirp.org or Online Submission Portal.
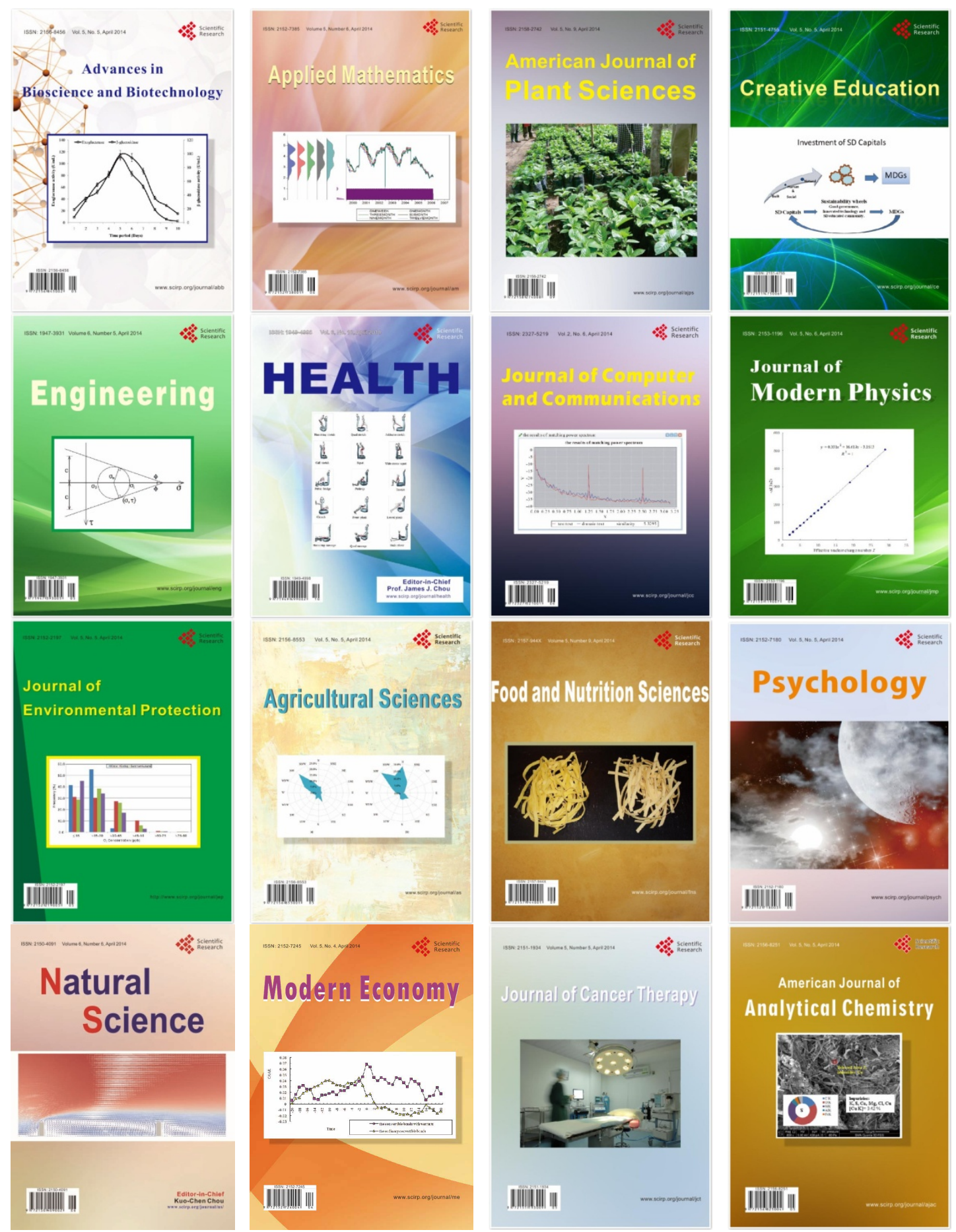